\title{
Spot Urine Osmolality/Creatinine Ratio in Healthy Humans
}

\author{
Srini Godevithanage ${ }^{\text {a }}$ Piyumi P. Kanankearachchia ${ }^{a} \quad$ Mahanama P. Dissanayake $^{a}$ \\ Thilak A. Jayalath ${ }^{b}$ Nimal Chandrasiri ${ }^{e}$ Rangani P. Jinasena ${ }^{c}$ \\ Ranjith PV. Kumarasiri ${ }^{d}$ Chulananda D.A. Goonasekera ${ }^{a}$ \\ Departments of a Anesthesiology, ${ }^{b}$ Medicine, ${ }^{c}$ Obstetrics and Gynecology, and ${ }^{\mathrm{d} C o m m u n i t y ~ M e d i c i n e, ~}$ \\ Faculty of Medicine, University of Peradeniya, and eVeterinary Research Institute, Peradeniya, Sri Lanka
}

\section{Key Words}

Osmolality $\cdot$ Creatinine $\cdot$ Spot urine $\cdot$ Renal concentrating ability

\begin{abstract}
Background: Spot urine albumin/creatinine ratio is a reliable estimate of 24-hour urine albumin excretion. In a pilot study, we observed that the spot urine osmolality/creatinine ratio $\left(U_{\text {osm }} / U_{c r}\right)$ in healthy adults is reproducible. Therefore, we postulated that $U_{\mathrm{osm}} / U_{\mathrm{cr}}$ of a spot urine sample may give an overall estimate of urinary excretion of solutes, renal concentrating ability and body hydration status. Method: Early morning spot urine samples were collected from healthy humans, frozen and analyzed in batches to establish spot $\mathrm{U}_{\mathrm{osm}} / \mathrm{U}_{\mathrm{cr}}$ and its variation in relation to sex, age, body weight and height. Results: Two hundred and twenty-nine healthy volunteers participated. They were stratified into seven age groups: (a) 1.5-5, (b) >5-10, (c) >10-20, (d) >20-30, (e) >30 45, (f) $>45-60$, and $(\mathrm{g})>60$ years. Fifteen males and $15 \mathrm{fe}-$ males were allocated to each age category. A spot urine sample was collected from all subjects in the morning after the first void and was analyzed for osmolality and creatinine. The influence of age, sex, body weight and height on spot $\mathrm{U}_{\mathrm{osm}} /$ $\mathrm{U}_{\mathrm{cr}}$ was investigated using multiple linear regression. Only height showed a significant correlation $\left(R^{2}=0.02\right)$. Further
\end{abstract}

analysis after excluding the 1.5-5 years age group revealed no significant correlation between age, sex, body weight and height and the $U_{o s m} / U_{c r}$ ratio. Conclusion: Spot $U_{o s m} /$ $U_{c r}$ of healthy humans is a consistent index in steady state and needs no correction for sex, age and body weight above the age of 5 years.

Copyright $\odot 2010$ S. Karger AG, Basel

\section{Introduction}

Spot urine albumin/creatinine ratio is a reliable estimate of 24-hour urine protein excretion since it accounts for the variability in urine concentration over time $[1,2]$. Similarly, urine uric acid/urine creatinine, urine calcium/urine creatinine ratios have been used to estimate urinary excretion of those substances [3]. Similarly, the urine osmolality/creatinine $\left(\mathrm{U}_{\mathrm{osm}} / \mathrm{U}_{\mathrm{cr}}\right)$ ratio of a spot urine sample may give an overall estimate of urinary excretion of solutes and renal concentrating ability. Renal concentrating status at a given time is dependent on the ability of the kidney to concentrate and the body fluid status. In steady state, urine excretion of creatinine is assumed to be a constant. Therefore, $\mathrm{U}_{\mathrm{osm}} / \mathrm{U}_{\mathrm{cr}}$ may give an estimate of renal concentrating function and body hydration status.

\section{KARGER \\ Fax +41613061234 E-Mail karger@karger.ch} www.karger.com

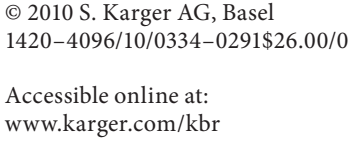

Prof. C.D.A. Goonasekera

Department of Anesthesiology, Faculty of Medicine

University of Peradeniya

Peradeniya 20400 (Sri Lanka)

Tel. +94 71277 1507, Fax +94 838 9106, E-Mail cgoonase@ slt.lk 
The overall aim of our study was to evaluate the suitability of $U_{o s m} / U_{c r}$ as an index of relevance in clinical practice. We anticipated that $\mathrm{U}_{\mathrm{osm}} / \mathrm{U}_{\mathrm{cr}}$ may be of value to monitor body hydration status or urine concentrating ability among patients over time.

Therefore, several aspects of $U_{\text {osm }} / U_{c r}$ were studied to investigate the following: (a) whether spot $U_{o s m} / U_{c r}$ is reproducible and consistent; (b) whether the $\mathrm{U}_{\mathrm{osm}} / \mathrm{U}_{\mathrm{cr}}$ ratio in a model disease state differs from that of healthy individuals; (c) whether $U_{o s m} / U_{c r}$ is variable with water loading and thus with hydration; (d) whether age, sex, height and weight have any influence on $\mathrm{U}_{\mathrm{osm}} / \mathrm{U}_{\mathrm{cr}}$ in healthy humans.

\section{Methods}

Written informed consent was obtained from all participants (as detailed in each subsection) after an explanation of the purpose of the study and the extent of their involvement. The research protocol was approved by the ethics committee of the Faculty of Medicine, University of Peradeniya, Sri Lanka. Spot urine samples of $1.5 \mathrm{ml}$ were collected in the morning hours after the first void into plastic containers and stored in Eppendorf tubes at $-20^{\circ} \mathrm{C}$ within $2 \mathrm{~h}$ of collection. Samples were analyzed in batches of 50 .

Urine creatinine concentration was determined by kinetic Jaffe reaction (alkaline pirate solution) using auto-analyzer [4]. The auto-analyzer was calibrated with standard solutions before each batch was run. Urine osmolality was measured by freezing point depression method via micro-osmometer [4]. The osmometer was calibrated with distilled water and standard solutions before analyzing each batch of samples. Two urine samples, one with high osmolality and the other with low osmolality were repeatedly analyzed within each batch and between batches to calculate within-assay variations (table 1 ).

To establish the consistency of $\mathrm{U}_{\mathrm{osm}} / \mathrm{U}_{\mathrm{cr}}$ in spot urine samples on repeated measurements, spot urine samples were obtained from volunteering healthy medical students in the morning hours consecutively over 4 days.

To establish the behavior of $\mathrm{U}_{\mathrm{osm}} / \mathrm{U}_{\mathrm{cr}}$ in a consistently abnormal state, urine was collected from the urinary catheters of mechanically ventilated patients (with the consent of next of kin) with organophosphate poisoning, between the 5th and 9th day of poisoning. These patients were otherwise healthy and had consumed organophosphate in an attempt at deliberate self-harm, and were in the intensive care units of the Teaching Hospitals Peradeniya and Kandy. The initial 4 days of poisoning were avoided as excreted metabolites of the poison itself may affect the urine osmolality.

A group of healthy volunteering university students participated in the experiment to establish whether $\mathrm{U}_{\mathrm{osm}} / \mathrm{U}_{\mathrm{cr}}$ varies with water loading. After obtaining a spot urine sample, they were given 1 liter of water to drink, and thereafter urine samples were collected from them at 1,2 and $3 \mathrm{~h}$ after water loading.

The study on the influence of age, sex, height and weight on spot $U_{\mathrm{osm}} / \mathrm{U}_{\mathrm{cr}}$ was conducted in healthy volunteers. Subjects with a history of hypertension, diabetes mellitus, chronic renal diseases, endocrine disease, urinary tract infection, diarrhea, vomit-
Table 1. Within-assay and inter-assay variations in urine osmolality and urine creatinine measurements

\begin{tabular}{lll}
\hline Measurement & $\begin{array}{l}\text { Within-assay } \\
\text { variation, \% }\end{array}$ & $\begin{array}{l}\text { Inter-assay } \\
\text { variation, \% }\end{array}$ \\
\hline Osmolality, mosm/l & $1.50 \pm 1.70$ & $1.24 \pm 1.45$ \\
Creatinine, mM & $1.05 \pm 0.37$ & $1.92 \pm 0.57$ \\
\hline
\end{tabular}

Values are expressed as mean $\pm \mathrm{SD}$.

ing, and subjects who were on medication that may interfere with renal creatinine excretion, such as cimetidine, trimethoprime, dapsone, nephrotoxic drugs and diuretics, were excluded. Thereafter, they were stratified according to the age.

One-month- to 5-year-old healthy children were recruited from two local clinics. They attended the clinics for routine vaccinations. Five- to 18-year-old healthy children and adolescents were recruited from local schools; 18 - to 30-year-old healthy subjects were university resident students, and others were local village people.

Age, sex and body weight were recorded on a standard form. All subjects above 2.5 years of age were weighed to the nearest kilogram using a bathroom scale. The children below 2.5 years were weighed using an eye level physician beam scale. The same scales were used throughout the study by the same observer.

SPSS 12.0 was used for statistics.

\section{Results}

\section{Reproducibility and Consistency of Spot $U_{\text {osm }} / U_{c r}$}

Early morning spot urine samples of $1.5 \mathrm{ml}$ were collected from 30 healthy adult volunteers ( 15 male, age $24-$ 28 years) over 4 consecutive days, and urine osmolality and creatinine concentrations were measured. Their mean (SD) urine osmolality was $540.17 \mathrm{mosm} \mathrm{l}^{-1}$ (289.55), and the mean (SD) creatinine was $10.20 \mathrm{mmol} \mathrm{l}^{-1}$ (8.14). Their mean (SD) $\mathrm{U}_{\text {osm }} / \mathrm{U}_{\mathrm{cr}}$ was $65.69 \mathrm{mosm} / \mathrm{mmol}$ (25.01).

On repeated measurements over 4 consecutive days, the same 30 healthy volunteers showed a mean (SE) early morning spot $U_{\text {osm }} / U_{c r}$ of 66.63 (5.38), 65.88 (4.8), 66.3 (3.9), 63.96 (4.2) $\mathrm{mosm} / \mathrm{mmol}$ on days $1-4$, respectively. Their mean $\mathrm{U}_{\mathrm{osm}} / \mathrm{U}_{\mathrm{cr}}$ was evidently constant on repeated measurements in steady state on the 4 consecutive days (fig. 1).

\section{$U_{\text {osm }} / U_{c r}$ in a Model Disease State and in Healthy} Individuals

Ten patients ( 8 male, mean age 31.6 years, range $14-54$ ) on mechanical ventilator were studied from the 5 th to the 


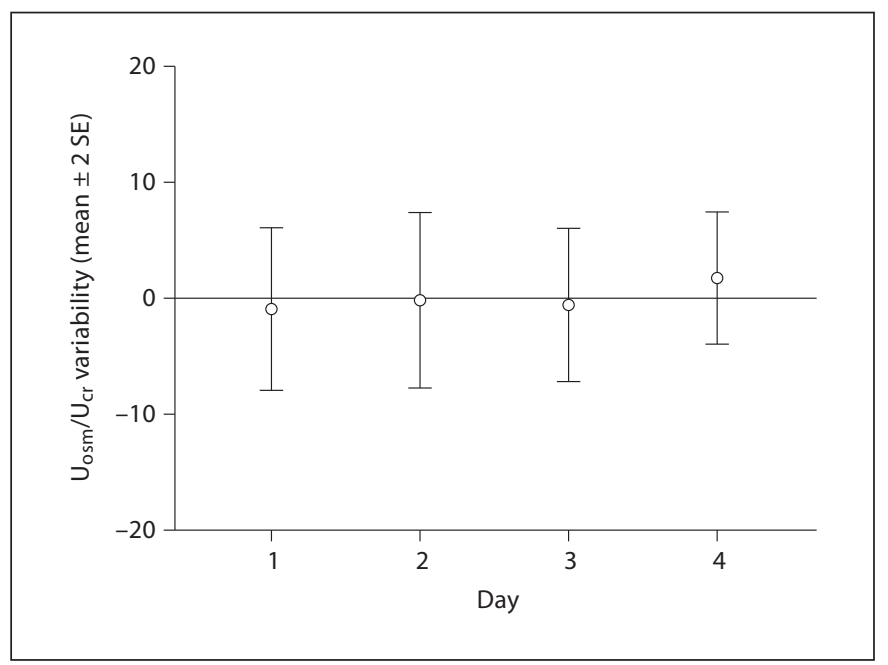

Fig. 1. Bland-Altman plot indicating the variation in spot $U_{o s m} /$ $\mathrm{U}_{\mathrm{cr}}$ among healthy humans $(\mathrm{n}=30)$ over 4 consecutive days.

Table 2. Sample distribution according to age (in years)

\begin{tabular}{lllllllll}
\hline \multicolumn{7}{c}{ Age group } & & \\
\cline { 2 - 7 } & $1.5-5$ & $>5-10$ & $>10-20$ & $>20-30$ & $>30-45$ & $>45-60$ & $>60$ \\
\hline Female & 17 & 17 & 19 & 24 & 14 & 18 & 3 \\
Male & 17 & 26 & 33 & 15 & 11 & 9 & 6 \\
\hline
\end{tabular}

8th day following organophosphate poisoning. They showed a mean (SD) $\mathrm{U}_{\text {osm }} / \mathrm{U}_{\text {cr }}$ of 135.62 (19.03), 138.4 (29.64), 132.03 (25.12), and 144.66 (22.15) $\mathrm{mosm} / \mathrm{mmol}$ on the 4 consecutive days, respectively. The mean (SD) $\mathrm{U}_{\text {osm }} /$ $\mathrm{U}_{\mathrm{cr}}$ in these patients was 137.68 (74.04) $\mathrm{mosm} / \mathrm{mmol}$, and was significantly higher than that of the 30 healthy adults [65.69 $\mathrm{mosm} / \mathrm{mmol}$ (25.01); $\mathrm{p}>0.0001,95 \%$ CI, 96.06 to $-47.91]$.

\section{Spot $U_{o s m} / U_{c r}$ Variability with Water Loading}

Twenty-one healthy university students (age 24-28 years) participated. All drank $1.0 \mathrm{l}$ of water, and urine samples were collected immediately before and $1,2,3 \mathrm{~h}$ after water loading. Their mean (SE) $\mathrm{U}_{\mathrm{osm}} / \mathrm{U}_{\mathrm{cr}}$ before and $1,2,3 \mathrm{~h}$ after water loading was 89.07 (42.53), 105.81 (33.00), 122.66 (48.57), and 100.13 (37.55) $\mathrm{mosm} / \mathrm{mmol}$. The rise in $\mathrm{U}_{\mathrm{osm}} / \mathrm{U}_{\mathrm{cr}}$ was statistically significant at $2 \mathrm{~h}$ after drinking water $(\mathrm{p}=0.004,95 \% \mathrm{CI},-55.19$ to -11.98 ; fig. 2$)$.

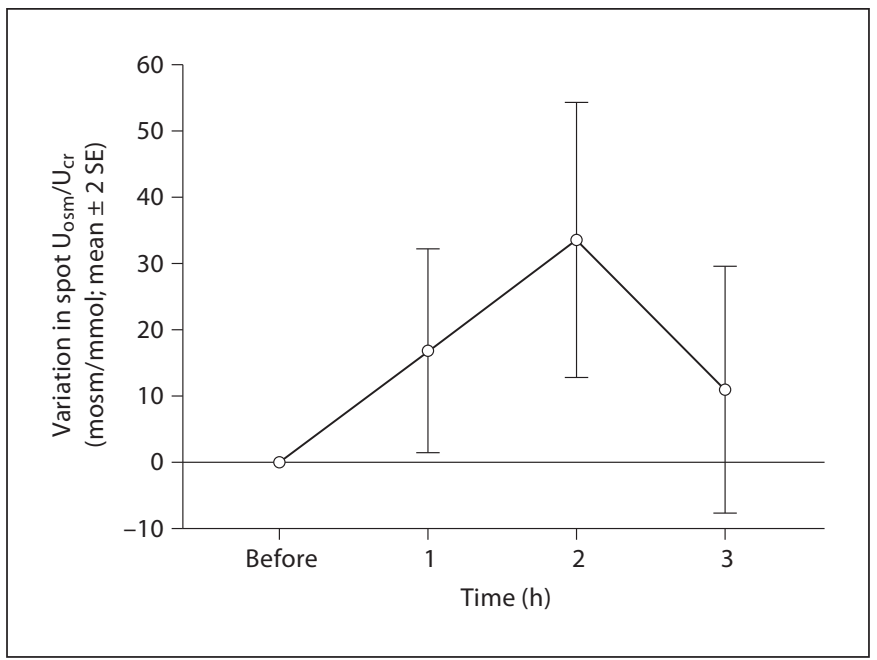

Fig. 2. Variation in spot $U_{o s m} / U_{c r}$ from baseline after drinking 1 liter of water among healthy adults $(n=21)$.

Influence of Age, Sex, Height and Weight on $U_{o s m} / U_{c r}$ among Healthy Humans

The influence of sex, age, body weight and height on the $\mathrm{U}_{\mathrm{osm}} / \mathrm{U}_{\mathrm{cr}}$ ratio was assessed using multiple linear regression.

The study was conducted in 229 healthy volunteers whose age distribution ranged from 1 month to 60 years. There were 112 females and 117 males in this study group (table 2). Their $\mathrm{U}_{\mathrm{osm}} / \mathrm{U}_{\mathrm{cr}}$ against each age category is shown in figure 3.

The influence of age, sex, body weight and height on the spot $U_{o s m} / U_{c r}$ ratio was investigated using multiple linear regression, and only height showed a significant correlation. $\mathrm{R}^{2}$ was 0.02 , suggesting that height may influence the $\mathrm{U}_{\mathrm{osm}} / \mathrm{U}_{\mathrm{cr}}$ ratio by $2 \%$. Further analysis after excluding the 1.5-5 years age group revealed no significant correlation between the $\mathrm{U}_{\mathrm{osm}} / \mathrm{U}_{\mathrm{cr}}$ ratio and age, sex, body weight and height.

\section{Discussion}

Urine osmolality measures the concentration of osmotically active particles in urine. The body hydration status and renal concentrating ability determine water content in urine and hence contribute to its osmolality. Thus, urine osmolality may give important information about a patient's fluid balance status.

Kidney Blood Press Res 2010;33:291-296 


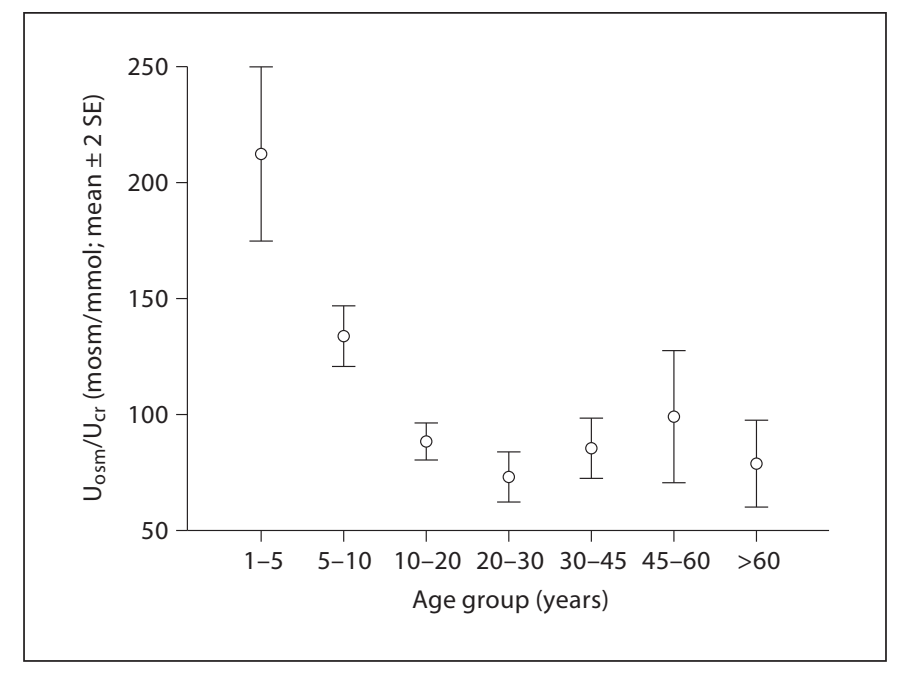

Fig. 3. Bar plot of spot $U_{o s m} / U_{c r}$ among different healthy age groups.

Reproducibility and Consistency of Spot $U_{\text {osm }} / U_{c r}$

Traditionally, measurement of urine osmolality and urinary solute concentrations in timed urine collections has been used to diagnose and monitor renal disorders. The same measurement in a spot urine sample has been used to assess body hydration status.

A 24-hour urine collection is commonly used as urine osmolality varies greatly over the day, but this is timeconsuming and often imprecise due to errors related to urine collection, especially in children. Our study concluded that $\mathrm{U}_{\mathrm{osm}} / \mathrm{U}_{\mathrm{cr}}$ is a reproducible entity, and it is a consistent urinary index in 'steady state' in healthy humans. This may therefore be an alternative approach avoiding timed or 24-hour urine collection. In this investigation, we did not embark upon a comparison of spot $\mathrm{U}_{\mathrm{osm}} / \mathrm{U}_{\mathrm{cr}}$ with a formal osmolar clearance study involving a 24-hour urine collection akin to similar studies that were undertaken when the validity of spot $U_{\mathrm{alb}} / \mathrm{U}_{\mathrm{cr}}$ was established. This is because (a) it has been observed that incomplete 24-hour specimens contribute to grossly erroneous results in such studies [5], and (b) it was unlikely that osmolar clearance in isolation would relate to $\mathrm{U}_{\text {osm }} /$ $\mathrm{U}_{\mathrm{cr}}$ as it was an overall estimate of body hydration status, renal concentrating ability as well as solute excretion at a unique time in the biological clock, i.e. early morning.

\section{$U_{\text {osm }} / U_{\text {cr }}$ in a Model Disease State and in Healthy}

Individuals

We observed that in organophosphate-poisoned patients spot $\mathrm{U}_{\mathrm{osm}} / \mathrm{U}_{\mathrm{cr}}$ values were consistently above nor- mal. Organophosphate poisoning is an acquired clinical condition resulting from oral ingestion of organophosphate compounds with intended self-harm. These patients are usually young and healthy before poisoning. Their clinical features include increased muscarinic effects and cardiorespiratory insufficiency especially during the initial few days. They usually stabilize and recover with supportive therapy. Although there are individual case reports of acute kidney injury with organophosphates, the patients recruited in this study did not have altered plasma renal function indices. Their mean blood urea during the study period was $2.92 \mathrm{mM}( \pm 1.33)$, and serum creatinine was $74( \pm 14.26) \mu \mathrm{M}$. It should also be noted that in our study this group of patients was considered a 'uniform' set with 'normal' primary laboratory indices of renal function.

A definitive causal relationship between organophosphate and renal injury has not been identified so far. However, in a case study, acute renal failure has been reported early within $72 \mathrm{~h}$ along with multiorgan failure [6], and was associated with high mortality [7]. On the other hand, organophosphates have been shown to cause renal tubular injury in vitro [8]. This might be the reason for the significant difference between their and normal $\mathrm{U}_{\mathrm{osm}} / \mathrm{U}_{\mathrm{cr}}$ values. Logically, this should result from either increased solute excretion or water retention via reabsorption. In this context, the above observation was unlikely to have resulted from a relative deficiency in hydration as their daily fluid intake from day 5 to day 8 was $4,489 \pm 1,027 \mathrm{ml}$, and urine output was 4,226 $\pm 1,310$ $\mathrm{ml}$ (mean $\pm \mathrm{SD}$ ). Being on a ventilator during the study period could be another confounding factor. Positive pressure ventilation alters a variety of neurohumoral systems including sympathetic outflow, renin-angiotensin axis, antidiuretic hormone, and atrial natriuretic peptide release, all ultimately leading to a state of salt and water retention [9]. Medications, intravenous fluids and nasogastric feeds also alter the normal excretion of solutes.

\section{Spot $U_{\text {osm }} / U_{c r}$ Variability with Water Loading}

The volunteering students were not fasting when the water loading was started, but did not receive any additional food or water during the study period. We anticipated that osmolality of urine would decrease with water loading, and that this dilution would peak at $2 \mathrm{~h}$ from water loading. Although the reduction in osmolality, with a proportional reduction in creatinine, should have kept $\mathrm{U}_{\mathrm{osm}} / \mathrm{U}_{\mathrm{cr}}$ constant, we observed a rise in this ratio, which could either be due to a relative reduction in the urine creatinine excretion or excess excretion of another 
osmotically active substance. In early experiments, it was observed that hydration is followed by increased urea excretion independent of the degree of increase in urine volume [10]. It is now known that $\mathrm{ADH}$ has direct regulatory effects on urea excretion [11]. The action of ADH increases the permeability of the distal nephron to water and urea in fasting adults, but returning a significant increase in natriuresis with hydration [12].

In this investigation, we noted that the mean $\mathrm{U}_{\mathrm{osm}} / \mathrm{U}_{\mathrm{cr}}$ ratio of the early morning spot urine samples of 30 healthy adults was $\sim 65 \mathrm{mosm} / \mathrm{mmol}$, whereas before water loading it was $\sim 89 \mathrm{mosm} / \mathrm{mmol}$. The water loading was done during the morning hours of the day from 9 a.m. to 12 noon, and the initial sample was not an early morning fasting sample. The $U_{\text {osm }} / U_{c r}$ reproducibility tests were done on early morning urine samples after a natural $\sim 10$ hour overnight fast. Therefore, the increase in $\mathrm{U}_{\mathrm{osm}} / \mathrm{U}_{\mathrm{cr}}$ that was noted in healthy subjects prior to water loading compared to the overnight fasting values is in fact a finding compatible with the observation made during water loading itself (fig. 2).

\section{Influence of Age, Sex, Height and Weight on Spot \\ $U_{o s m} / U_{c r}$ among Healthy Humans}

The production of creatinine is related to lean body mass, which generally does not change within a relatively short period of time $[13,14]$. When creatinine concentrations are constant, the glomerular filtration rate is stable, and tubular secretion and reabsorption of creatinine (in health at most ages) are minimal. Therefore, the rate of elimination of creatinine from the body does not vary much. This steady state is the rationale for using urinary creatinine concentration as a reference standard for the chemical analysis of spot urine [15]. Since lean body mass is variable with age and sex of an individual, it may have an effect on the $\mathrm{U}_{\text {osm }} / \mathrm{U}_{\mathrm{cr}}$ ratio. Therefore, our study was set out to see the influence of age, sex, body weight and height on spot $U_{o s m} / U_{c r}$ in healthy humans.

The results clearly show a greater scatter in the spot $\mathrm{U}_{\mathrm{osm}} / \mathrm{U}_{\mathrm{cr}}$ values during the early years of life, with higher values of standard error of mean. This is particularly true in the neonatal period where creatinine excretion is highly viable confounded by maternal creatinine at birth and rapidly changing GFR (almost doubling within 2 weeks) [16]. This is in contrast to the picture seen in older children and adults, where $U_{o s m} / U_{c r}$ remains relatively constant with less scatter.

Multiple linear regression indicates that among the variables tested only body height is significantly correlated with the $U_{o s m} / U_{c r}$ ratio. No significant correlation between $U_{\text {osm }} / U_{\text {cr }}$ and age, sex and body weight was found. $\mathrm{R}^{2}$ was 0.02 , suggesting that height may influence spot $U_{\text {osm }} / U_{\text {cr }}$ by $2 \%$. Since there was more variability in the $U_{o s m} / U_{c r}$ ratio in younger age groups, further analysis was done using multiple linear regression after excluding the 1.5-5 years age group. In this analysis, no significant correlation was observed between the $\mathrm{U}_{\mathrm{osm}} / \mathrm{U}_{\mathrm{cr}}$ ratio and age, sex, body weight and height. This is probably due to the difference in tubular handling of creatinine in the younger age group compared to older children and adults with mature kidneys.

Whatever the pathophysiological explanation for changes in the spot $U_{\text {osm }} / U_{c r}$ ratio in the young, our observations guide us to conclude that the spot $U_{o s m} / U_{c r}$ ratio needs no correction for sex, age, body weight or height in those who are above the age of 5 years.

Thus, spot $\mathrm{U}_{\mathrm{osm}} / \mathrm{U}_{\mathrm{cr}}$ measurement is at least as reliable as 24-hour urinary osmolality in predicting renal concentrating ability and assessing body hydration status in older children. In addition, it is easier to perform, less time-consuming, sensitive and relatively inexpensive $[5$, 17]. In the same individual, serial measurements of $U_{\text {osm }} /$ $\mathrm{U}_{\mathrm{cr}}$ may be useful to evaluate his/her renal concentrating ability in steady state.

\section{Conclusion}

Spot $\mathrm{U}_{\mathrm{osm}} / \mathrm{U}_{\mathrm{cr}}$ is a reproducible entity in steady state and needs no correction for sex, age, body weight or height in individuals above 5 years of age.

\section{Acknowledgments}

We thank Prof. N. Rathnathunga for laboratory assistance. This project was supported by the National Science Foundation of Sri Lanka.

References

Kidney Blood Press Res 2010;33:291-296 Receiver operating characteristic curve analysis favors albumin-to-creatinine ratio over albumin concentration. Diabetes Care 1999;22:307-313.

2 Ruggenenti P, Gaspari F, Perna A, Remuzzi G: Cross-sectional longitudinal study of spot morning urine protein:creatinine ratio, 24 hour urine protein excretion rate, glomerular filtration rate, and end stage renal failure in chronic renal disease in patients without diabetes. BMJ 1998;316:504-509. 
3 Penido MG, Diniz JS, Guimarães MM, Cardoso RB, Souto MF, Penido MG: Urinary excretion of calcium, uric acid and citrate in healthy children and adolescents (in Portuguese). J Pediatr (Rio J) 2002;78:153-160.

4 Bland JM, Altman DG: Statistical methods for measuring agreement between two methods of clinical measurement. Lancet 1986;1: 307-310.

5 Ginsberg JM, Chang BS, Matarese RA, Garella S: Use of single voided urine samples to estimate quantitative proteinuria. New Eng J Med 1983;309:1543-1546.

6 Agostini M, Bianchin A: Acute renal failure from organophosphate poisoning: a case of success with haemofiltration. Hum Exp Toxicol 2003;22:165-167.

7 Munidasa UADD, Gawarammana IB, Kularatne SAM, Kumarasiri PVR, Goonasekera CDA: Survival pattern in patients with acute organophosphate poisoning receiving intensive care. J Toxicol Clin Toxicol 2004; 42:343-347.
Poovala VS, Huang H, Salahudeen AK: Role of reactive oxygen metabolites in organophosphate-bidrin-induced renal tubular cytotoxicity. J Am Soc Nephrol 1999;10:17461752.

$\checkmark 9$ Koyner JL, Murray PT: Mechanical ventilation and lung-kidney interactions. Clin J Am Soc Nephrol 2008;3:562-570.

10 Addis T, Watanabe CK: The effect of changes in the volume of urine on the rate of urea excretion. J Biol Chem 1917, www.jbc.org/cgi/ reprint/29/3/399.pdf; accessed 15th June 2009

11 Nielsen S, Knepper MA: Vasopressin activates collecting duct urea transporters and water channels by distinct physical processes. Am J Physiol 1993;265:F204-F213.

12 Anastasio P, Cirillo M, Spitali L, Frangiosa A, Pollastro RM, De Santo NG: Level of hydration and renal function in healthy humans. Kidney Int 2001;60:748-756.
13 Miller AT Jr, Blyth CS: Estimation of lean body mass and body fat from basal oxygen consumption and creatinine excretion. J Appl Physiol 1952;5:73-78.

14 Sutphen JL: Anthropometric determinants of creatinine excretion in preterm infants. Pediatr 1982;69:719-723.

15 Vestergaard P, Leverett R: Constancy of urinary creatinine excretion. J Lab Clin Med 1958;51:211-218.

-16 Matos V, Drukker A, Guignard JP: Spot urine samples for evaluating solute excretion in the first week of life. Arch Dis Child Fetal Neonatal Ed 1999;80:F240-F242.

17 Kaufman JM, Greene ML, Seegmiller JE: Urine uric acid to creatinine ratio - a screening test for inherited disorders of purine metabolism. Phosphoribosyltransferase (PRT) deficiency in X-linked cerebral palsy and in a variant of gout. J Pediatr 1968;73:583-592. 